\title{
Produtividade de Massa e Dessecação de Forrageiras Perenes PARA INTEGRAÇÃo LAVOURA-PECUÁRIA ${ }^{1}$
}

\author{
Mass Yield and Burndown of Perennial Forages for Crop-Livestock Integration \\ CECCON, G. ${ }^{2}$ e CONCENÇO, G. ${ }^{2}$
}

\begin{abstract}
RESUMO - A viabilidade da sucessão soja-milho safrinha em plantio direto no cerrado depende de adequada produção de resíduos na superficie do solo, o que pode ser obtido através do cultivo consorciado de milho com forrageira perene. Objetivou-se neste trabalho avaliar a produtividade de massa e a facilidade para dessecação de nove forrageiras perenes. As espécies foram cultivadas em consórcio com milho safrinha, de março a julho de 2009. Em outubro, as plantas foram cortadas a 0,20 $\mathrm{m}$ do solo, e 20 dias após foram aplicadas as doses de glyphosate $\left(0,72,1,44,2,06\right.$ e 2,88 kg e.a. ha $\left.{ }^{-1}\right)$. O efeito das doses foi avaliado aos 10 e 20 dias após a dessecação, mediante pesagem e secagem da massa em estufa a $60{ }^{\circ} \mathrm{C}$. O controle foi considerado excelente quando a umidade das plantas dessecadas estava menor ou igual a 30\%; assim, as forrageiras foram separadas em três grupos por facilidade de dessecação, sendo: 1) Urochloa (Syn Brachiaria) ruziziensis, Megatyrsus (syn Panicum) maximum cv. Massai e $M$. maximum cv. Aruana, com excelente resultado; 2) U. decumbens cv. Basilisk, U. brizantha cv. Xaraés e $U$. brizantha cv. Marandu, de moderada facilidade; e 3) $M$. maximum cv. Tanzânia, M. maximum cv. Mombaça e U. brizantha cv. Piatã, de difícil dessecação. Considerando a produtividade de massa, o menor período entre dessecação e avaliação e a dose de herbicida, destacam-se U.ruziziensis $\left(0,45\right.$ e $1,29 \mathrm{~kg}$ e.a. ha $\left.{ }^{-1}\right)$ e $M$. maximum cv. Aruana $(1,41 \mathrm{e}$ 1,66 kg e.a. ha-1) como de fácil dessecação, visando à semeadura da soja em sucessão.
\end{abstract}

Palavras-chave: Urochloa, Brachiaria, Panicum, Megatirsus, glyphosate.

\begin{abstract}
The feasibility of soybean-maize succession under the no-till system in the Brazilian cerrado depends on adequate amounts of straw on the soil surface, which can be obtained by intercropping maize with perennial forages. This study aimed to evaluate mass yield and burndown easiness for nine perennial forage species. The species were grown intercropped with maize from March to July 2009. In October, plants were cut at $0.20 \mathrm{~m}$ above ground and 20 days after cut, glyphosate was applied at the following doses: $0.72,1.44,2.06$, and $2.88 \mathrm{~kg}$ a.e. ha $\mathrm{h}^{-1}$ ). The effect of the doses was evaluated 10 and 20 days after application, by weighing and oven-drying the straw at $60{ }^{\circ} \mathrm{C}$. Control was considered excellent when moisture of the desiccated plants was less than or equal to $30 \%$ and the forages were grouped according to burn-down easiness: 1) Urochloa (Syn Brachiaria) ruziziensis, Megatyrsus (syn Panicum) maximum cv. Massai, and M. maximum cv. Aruana as the most easily controlled; 2) U. decumbens $c v$. Basilisk, $\boldsymbol{U}$. brizantha $c v$. Xaraés, and $\boldsymbol{U}$. brizantha $c v$. Marandu, as intermediary; and 3) M. maximum cv. Tanzânia, M. maximum cv. Mombaça, and B. brizantha cv. Piatã, as the hardest-to-kill. Considering biomass production, the shorter interval between herbicide application and plant death, and the glyphosate dose, $\boldsymbol{U}$. ruziziensis $\left(0.45\right.$ and $1.29 \mathrm{~kg}$ a.e. ha $\mathrm{H}^{-1}$ ) and $\boldsymbol{M}$. maximum $\mathrm{cv}$. Aruana (1.41 and $1.66 \mathrm{~kg}$ a.e. $\left.\mathrm{ha}^{-1}\right)$ presented the most burn-down easiness, aiming at soybean plant succession.
\end{abstract}

Keywords: Brachiaria, Urochloa, Panicum, Megatirsus, glyphosate.

Recebido para publicação em 22.9.2013 e aprovado em 6.12.2013.

Embrapa Agropecuária Oeste, Dourados-MS, Brasil, <gessi.ceccon@embrapa.br>.

Planta Daninha, Viçosa-MG, v. 32, n. 2, p. 319-326, 2014 


\section{INTRODUÇÃO}

Forrageiras perenes dos gêneros Brachiaria e Panicum podem ser utilizadas para produção de palha ou pasto durante o período seco na região do cerrado (Machado \& Assis, 2010), proporcionando a integração das atividades de lavoura e pecuária. O consórcio de milho safrinha com forrageiras perenes é uma alternativa para manter o rendimento de grãos de milho e produzir palha durante e após a colheita do milho, devido ao crescimento da forrageira até sua dessecação para semeadura da soja (Ceccon et al., 2013).

A dessecação de forrageiras perenes deve ser realizada preferencialmente com produtos sistêmicos, como glyphosate, em doses apropriadas para cada espécie (Kozlowski, 2001). Nesse sentido, Jakelaitis et al. (2005) avaliaram a eficiência de sulfosate e glyphosate na dessecação de espécies forrageiras e plantas daninhas com diferentes doses e volumes de calda e observaram que o volume de calda não interferiu na eficiência dos herbicidas, sendo $U$. decumbens eficientemente controlada com duas aplicações de $1,0 \mathrm{~kg} \mathrm{ha}^{-1}$ de glyphosate, avaliada 21 dias após a aplicação. No entanto, algumas espécies podem liberar substâncias químicas com efeito alelopático após a dessecação e ser prejudiciais ao desenvolvimento das plantas (Souza Filho et al., 1997), como $U$. decumbens (Souza et al., 2006).

Para Damin et al. (2008), plantas de $U$. decumbens dessecadas com glyphosate e glufosinato de amônio apresentaram menor acúmulo de $\mathrm{N}$ em relação às plantas não dessecadas, o que pode ser atribuído às perdas de compostos nitrogenados pela exsudação radicular e ação direta dos herbicidas na parte aérea da forrageira. Isso indica que o período entre a dessecação e a semeadura pode interferir no desenvolvimento da cultura em sucessão.

Na dessecação de plantas daninhas, Constantin et al. (2009) verificaram melhor desempenho da soja com dessecação antecipada em 30 dias, mais uma aplicação feita no dia anterior à semeadura, com doses de 1,08 e 1,26 kg e.a. ha-1 de glyphosate, comparativamente com a dessecação realizada exclusivamente no dia anterior à semeadura. Contudo, em presença exclusiva de $U$. brizantha, Silva et al. (2006) constataram melhor desempenho da soja em semeadura realizada a partir de 14 dias após a dessecação, com dose de 1,44 kg e.a. ha-1 de glyphosate. Para Timossi et al. (2006), U. decumbens e $U$. brizantha $\mathrm{cv}$. Marandu apresentaram boa porcentagem de controle com dose de 2,16 kg e.a. ha ${ }^{-1}$ de glyphosate.

Quanto à dessecação de U. decumbens, Nunes et al. (2009) verificaram que a época mais adequada para isso está entre 7 e 14 dias antes da semeadura da soja, com dose de 1,3 kg e.a. ha-1 de glyphosate, assim como Santos et al. (2007) verificaram o mesmo intervalo para $U$. brizantha $\mathrm{cv}$. Marandu, porém com dose de 2,88 kg e.a. ha-1. Para $U$. ruziziensis, a semeadura da soja proporcionou maior rendimento de grãos da cultura com semeadura aos 11 dias após a dessecação, com dose de 1,92 kg e.a. ha ${ }^{-1}$ de glyphosate (Ceccon et al., 2009).

Para dessecação de $M$. maximum, Velini et al. (2000) constataram menor controle das plantas, comparativamente a $U$. decumbens. Machado \& Assis (2010), em avaliação feita aos 21 dias após a dessecação com 1,08 kg e.a. ha ${ }^{-1}$ de glyphosate, verificaram maior controle de $U$. ruziziensis, seguida de $U$. decumbens, $U$. brizantha cv. Marandu e Xaraés, pelo M. maximum cv. Tanzânia e depois pelo cv. Mombaça. No entanto, Ferreira et al. (2010), utilizando a mesma dose empregada por Machado \& Assis (2010), encontraram resultados divergentes, com maior eficiência na dessecação de $U$. brizantha cv. Piatã, MG4 e Marandu e M. maximum cv. Mombaça, seguidas por M. maximum cv. Tanzânia e Massai, $U$. decumbens e $U$. brizantha cv. Xaraés.

A modalidade de cultivo, solteiro ou consorciado, interfere na quantidade de massa produzida; a época de dessecação e a dose de herbicida interferem na eficiência da dessecação; logo, torna-se essencial para o sucesso da operação de plantio e estabelecimento da cultura definir dose e momento de aplicação do herbicida dessecante em função da espécie utilizada e de seu volume de massa.

O trabalho foi realizado com o objetivo de avaliar a produtividade de massa de espécies 
forrageiras perenes durante o outono-inverno e o efeito de doses de glyphosate para dessecação da rebrota, visando ao cultivo de soja em sucessão.

\section{MATERIAL E MÉTODOS}

O trabalho foi realizado em Dourados-MS, nas coordenadas de $22^{\circ} 13^{\prime}$ sul e $54^{\circ} 48^{\prime}$ oeste, a $400 \mathrm{~m}$ de altitude, em solo classificado como Latossolo Vermelho distroférrico, textura argilosa.

As espécies forrageiras foram cultivadas durante o outono-inverno de 2009, em linhas intercaladas ao milho safrinha, com espaçamento de $0,90 \mathrm{~m}$. O milho e as forrageiras foram semeados em 20 de março e colhidos em agosto de 2009. Em 29 de outubro, as forrageiras foram roçadas a $0,20 \mathrm{~m}$ do solo, simulando a retirada da forragem pelos animais, e 20 dias depois foi avaliado o rendimento de massa seca da rebrota, em três repetições de $0,9 \mathrm{~m}^{2}$; posteriormente, foi realizada a aplicação das doses do herbicida glyphosate.

O delineamento experimental foi em blocos ao acaso, com parcelas subdivididas. As espécies forrageiras foram alocadas nas parcelas principais, e as doses, nas subparcelas, em unidades experimentais de 5,4 x $6 \mathrm{~m}$, com três repetições. As forrageiras utilizadas foram: 1) ruziziensis (Urochloa (Syn Brachiaria) ruziziensis cv. Comum), 2) decumbens (U. decumbens cv. Basilisk), 3) marandu (U. brizantha cv. Marandu), 4) xaraés (U. brizantha cv. Xaraés), 5) piatã (U. brizantha cv. Piatã), 6) aruana (Megatyrsus (Syn Panicum) maximum cv. Aruana), 7) massai ( $M$. maximum $\mathrm{x} P$. infestans cv. Massai), 8) tanzânia (M. maximum cv. Tanzânia) e 9) mombaça (M. maximum cv. Mombaça). As doses do herbicida glyphosate $(0,72,1,44,2,16$ e $2,88 \mathrm{~kg}$ e.a. $\mathrm{ha}^{-1}$ ) foram aplicadas no dia $19 \mathrm{de}$ novembro, utilizando pulverizador costal pressurizado com $\mathrm{CO}_{2}$, a pressão constante de $40 \mathrm{lb} \mathrm{pol}^{2}$, equipado com quatro pontas modelo Teejet da série 110.02 , espaçadas de $0,5 \mathrm{~m} \mathrm{e}$ calibradas para aplicar o equivalente a $150 \mathrm{~L} \mathrm{ha}^{-1}$ de calda. As pulverizações foram feitas entre 7 e 8 horas, com temperatura média de $26,7^{\circ} \mathrm{C}$ e umidade relativa média de $78,5 \%$.
Durante a realização do experimento, foram registradas as seguintes precipitações pluviométricas $(\mathrm{mm})$ : março $(56)$, abril $(0,0)$, maio (56), junho (53), julho (124), agosto (140), setembro (49), outubro (241) e novembro (239) (Embrapa, 2012), o que proporcionou avaliar as espécies em condições normais de crescimento.

O efeito das doses do herbicida ou controle das espécies forrageiras foram avaliados aos 10 e 20 dias após a dessecação, mediante corte das plantas rente ao solo e imediata aferição da massa verde em três repetições de $0,9 \mathrm{~m}^{2}$; as amostras foram secas em estufa com circulação forçada de ar durante 72 horas, para aferição da massa seca, em balança analítica, e determinação do conteúdo de água pela fórmula:

$$
C A \%=100 * \frac{(M F-M S)}{M F}
$$

em que $\mathrm{CA} \%$ = conteúdo de água em porcentagem, $\mathrm{MF}=$ massa fresca e MS = massa seca da forrageira (Rieffel Filho et al., 2006). Assim, foi possivel identificar a morte das plantas como um todo, e não apenas o percentual de folhas secas.

Em se tratando de forrageiras perenes, avaliações realizadas com base no conteúdo de água podem indicar com maior precisão o estado vegetativo das plantas (Rieffel Filho et al., 2006). Comparativamente com SBCS (1995) e Rieffel Filho et al. (2006), os maiores valores de conteúdo de água nas plantas correspondem aos menores controles; no presente trabalho, o conceito A (dessecação excelente) corresponde ao conteúdo de água menor ou igual a $30 \%$; B (dessecação moderada), ao conteúdo de água entre 31 e 40\%; C (dessecação deficiente), ao conteúdo de água entre 41 e 50\%; D (controle inexpressivo), ao conteúdo de água entre 51 e 60\%; e E (ausência de controle), ao conteúdo de água maior que $60 \%$. Com isso, foi estabelecido controle excelente quando a umidade era igual ou menor que $30 \%$, considerando plantas completamente mortas.

Os resultados foram submetidos à análise de variância; as médias de produtividade de massa das forrageiras, comparadas pelo teste de Tukey $(\leq 0,05)$; e as médias de dessecação, 
ajustadas por um modelo de regressão polinomial de melhor ajuste.

\section{RESULTADOS E DISCUSSÃO}

Houve efeito de espécies para produtividade de massa durante a condução do consórcio e também da massa da rebrota antes da dessecação, porém a presença das forrageiras não afetou a produtividade de massa e de grãos do milho safrinha (Tabela 1). Esses resultados estão de acordo com os de Ceccon et al. (2013), por não apresentarem redução significativa na produtividade do milho, e com os de Machado et al. (2010), por diferirem entre si quanto à produtividade em cultivo solteiro após a colheita do milho.

O maior rendimento de massa seca das forrageiras foi verificado pela xaraés, sem diferir estatisticamente da massa do mombaça e da ruziziensis. O rendimento total de massa (milho + forrageira) foi maior no consórcio com xaraés, sem diferir do consórcio com mombaça, tanzânia, marandu, ruziziensis ou com piatã, ao passo que as menores produtividades foram observadas no consórcio com massai (Tabela 1), corroborando resultados de Machado et al. (2010).
A maior produtividade de massa da rebrota foi observada no mombaça, enquanto as demais forrageiras não diferiram entre si. Ferreira et al. (2010) verificaram produtividades semelhantes, mas nesse trabalho o maior crescimento inicial do mombaça pode ser uma estratégia para maior oferta de pasto em período inicial em sistemas de integração lavoura-pecuária.

Houve interação significativa entre forrageiras e doses de glyphosate para conteúdo de água na massa das espécies, nas avaliações realizadas aos 10 e aos 20 dias após a dessecação (Figuras 1, 2 e 3).

$\mathrm{Na}$ primeira avaliação, não foi possível identificar uma dose de herbicida capaz de reduzir o conteúdo de água nas plantas a 30\% em marandu, xaraés e piatã (Figura 1). Para decumbens (Figura 2), a curva de resposta a doses de herbicida foi ajustada pelo modelo linear, ao passo que o modelo quadrático ajustou-se melhor para ruziziensis, aruana (Figura 2), massai, tanzânia e mombaça (Figura 3); contudo, para mombaça, a curva indicou umidade superior a $30 \%$ em todas as doses avaliadas. Em decumbens, tanzânia, mombaça, marandu, xaraés e piatã não foi

Tabela 1 - Rendimento de massa seca de forrageiras durante o consórcio com milho safrinha (RMF), rendimento total de massa seca da forrageira e do milho safrinha (RMT), rendimento de massa seca da rebrota, após o consórcio e após o corte (RMSR), e altura de plantas rebrotadas (APR) das espécies forrageiras, em Dourados-MS, 2009

\begin{tabular}{|c|c|c|c|c|}
\hline \multirow{2}{*}{ Espécie } & RMF & RMT & RMSR & APR \\
\hline & \multicolumn{2}{|c|}{$\left(\mathrm{kg}\right.$ e.a. $\left.\mathrm{ha}^{-1}\right)$} & \multicolumn{2}{|c|}{$(\mathrm{cm})$} \\
\hline U. ruziziensis cv. comum & $3.613 \mathrm{ab}$ & $5.965 \mathrm{ab}$ & $1.529 \mathrm{~b}$ & $41 \mathrm{c}$ \\
\hline U. decumbens cv. Basilisk & $2.285 \mathrm{bc}$ & $4.950 \mathrm{bc}$ & $1.470 \mathrm{~b}$ & $45 \mathrm{bc}$ \\
\hline U. brizantha cv. Marandu & $3.499 \mathrm{~b}$ & $6.409 \mathrm{ab}$ & $1.697 \mathrm{~b}$ & $43 \mathrm{c}$ \\
\hline U. brizantha cv. Xaraés & $5.775 \mathrm{a}$ & $8.131 \mathrm{a}$ & $1.835 \mathrm{~b}$ & $50 \mathrm{bc}$ \\
\hline U. brizantha cv. Piatã & $3.230 \mathrm{~b}$ & $5.912 \mathrm{ab}$ & $1.556 \mathrm{~b}$ & $47 \mathrm{bc}$ \\
\hline M. maximum cv. Aruana & $2.278 \mathrm{bc}$ & $4.471 \mathrm{bc}$ & $1.494 \mathrm{~b}$ & $47 \mathrm{bc}$ \\
\hline M. maximum cv. Massai & $919 \mathrm{~cd}$ & $3.260 \mathrm{c}$ & $1.083 \mathrm{~b}$ & $49 \mathrm{bc}$ \\
\hline M. maximum cv. Tanzânia & $3.391 \mathrm{~b}$ & $5.797 \mathrm{ab}$ & $1.694 \mathrm{~b}$ & $55 \mathrm{ab}$ \\
\hline M. maximum $\mathrm{cv}$. Mombaça & $4.307 \mathrm{ab}$ & $6.589 \mathrm{ab}$ & $3.150 \mathrm{a}$ & $61 \mathrm{a}$ \\
\hline Milho safrinha solteiro & $0 \mathrm{~d}$ & $3.006 \mathrm{c}$ & - & - \\
\hline Média & 2.930 & 5.449 & 1.723 & 49 \\
\hline $\mathrm{CV}(\%)$ & 30,7 & 23,3 & 18,1 & 7,3 \\
\hline
\end{tabular}

Médias seguidas da mesma letra, na coluna, não diferem pelo teste de Tukey a $5 \%$ de probabilidade. 

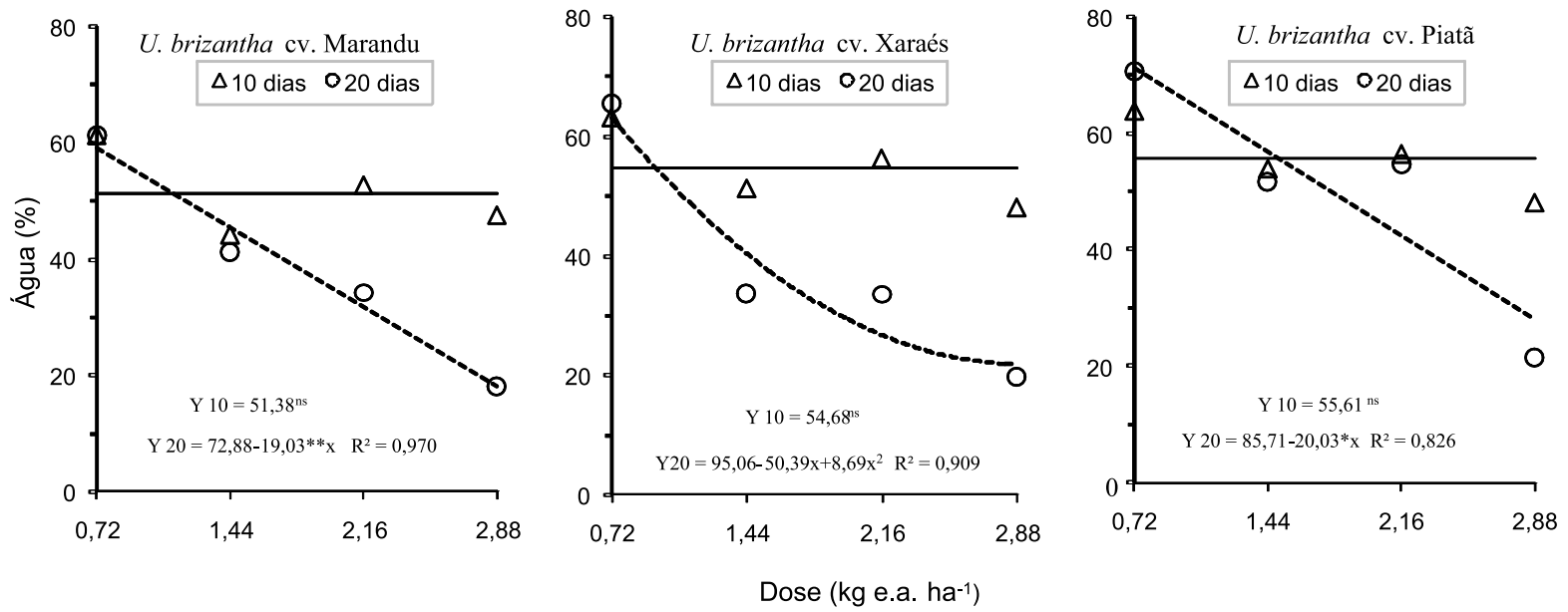

Figura 1 - Conteúdo de água na palha de Urochloa brizantha cv. Marandu, cv. Xaraés e cv. Piatã, aos 10 e 20 dias após a dessecação com doses de glyphosate, em sistema de ILP, em Dourados-MS.
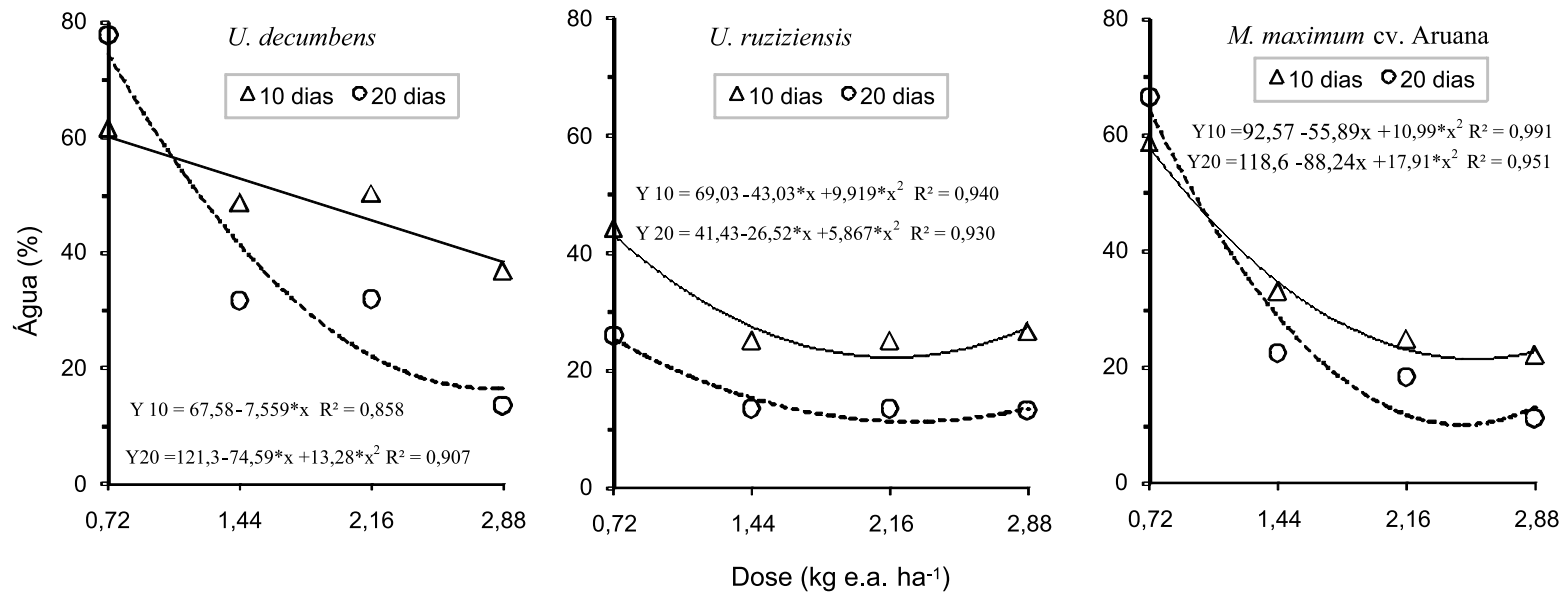

Figura 2 - Conteúdo de água na palha de Urochloa decumbens cv. Basilisk, U. ruziziensis cv. comum e Megatyrsus maximum cv. Aruana, aos 10 e 20 dias após a dessecação com doses de glyphosate, em sistema de ILP, em Dourados-MS 2009.
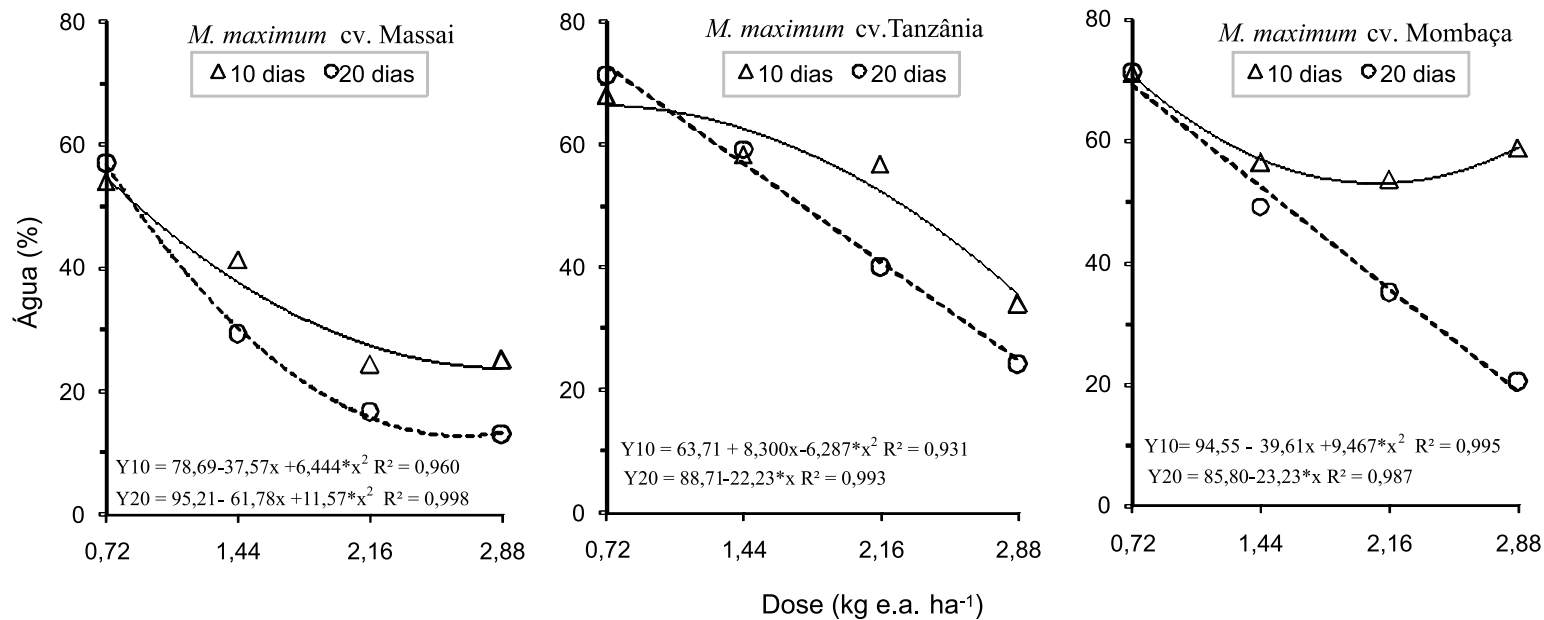

Figura 3 - Conteúdo de água na palha de M. maximum cv. Massai, cv. Tanzânia e cv. Mombaça, aos 10 e 20 dias após a dessecação com doses de equivalente ácido de glyphosate, em sistema de ILP, em Dourados-MS. 
possivel identificar dose adequada para redução a 30\% de água na massa das plantas, porque as doses ótimas estavam além das aplicadas.

$\mathrm{Na}$ segunda avaliação, com as doses avaliadas, o controle de marandu, piatã e tanzânia apresentou comportamento linear em função das doses de glyphosate; para xaraés, decumbens, ruziziensis, aruana e massai, o modelo quadrático foi o mais adequado (Figuras 1, 2 e 3).

Considerando que algumas plantas liberam exsudatos (Damin et al., 2008) e podem inibir o desenvolvimento de outras plantas (Souza Filho et al., 1997; Voll et al., 2009), deve-se observar um período de tempo entre a dessecação e a semeadura para evitar esses possíveis efeitos alelopáticos na cultura semeada em sucessão, sendo ideal que o plantio seja realizado quando as plantas já estiverem completamente controladas pelo herbicida.

$\mathrm{Na}$ avaliação realizada aos dez dias, apenas em cinco espécies foi possivel encontrar a dose para dessecação total; ruziziensis, massai e aruana apresentaram controle excelente, nas doses de 1,29, 1,66 e 1,94 kg e.a. ha ${ }^{-1}$ de glyphosate, respectivamente, seguidos por tanzânia e decumbens, nas doses de 3,05 e $4,97 \mathrm{~kg}$ e.a. ha ${ }^{1}$.

$\mathrm{Na}$ avaliação feita aos 20 dias após a dessecação, outras espécies foram consideradas como eficientemente controladas, com a seguinte ordem e respectivas doses, em $\mathrm{kg}$ e.a. ha ${ }^{-1}$ de glyphosate: ruziziensis $(0,45)$, decumbens $(1,22)$, aruana $(1,41)$, massai $(1,43)$, xaraés $(1,94)$, marandu $(2,25)$, mombaça $(2,40)$, tanzânia $(2,63)$ e piatã $(2,78)$.

As doses para controle eficiente determinadas no presente estudo foram aplicadas sobre plantas em estádio de rebrote após o corte, em pleno crescimento inicial. Nessas condições, o metabolismo do vegetal está mais ativo devido à necessidade de crescimento, o que aumenta a eficiência da dessecação e reduz o percentual de rebrota das plantas. Plantas submetidas a pastejo podem necessitar de doses diferenciadas de glyphosate para controle eficiente, caso tenham sofrido pisoteio excessivo e não seja destinado tempo para o rebrote da forrageira.
De maneira geral, vale a informação de que a maior dose e o maior tempo são mais eficientes para dessecação (Jakelaitis et al., 2005); no entanto, a correta escolha da espécie forrageira torna possível dessecação eficiente com menor dose no menor tempo após aplicação. Algumas plantas apresentaram baixo conteúdo de água já aos dez dias após a aplicação, como ruziziensis (42\%) e massai (58\%). Quanto às demais espécies, a menor dose de glyphosate $(0,72 \mathrm{~kg}$ e.a. ha-1) não foi eficiente em reduzir o conteúdo de água das plantas. Para xaraés, marandu, decumbens, tanzânia, mombaça e piatã, que mostravam alto conteúdo de água (62 a 70\%) nas menores doses, o aumento da dose do herbicida ou do tempo entre a aplicação e o plantio é importante para a efetiva morte da forrageira.

A dose predominante para dessecação de forrageiras encontrada na literatura é ampla e varia de 1,30 a $2,88 \mathrm{~kg}$ e.a. ha-1 de glyphosate, como avaliações realizadas entre 13 e 21 dias após a dessecação (Ceccon et al., 2009; Nunes et al., 2009; Ferreira et al., 2010; Machado \& Assis, 2010).

No presente trabalho a dose também é ampla, quando consideradas as espécies e o período de avaliação; contudo, ruziziensis, massai e aruana foram eficientemente controlados aos 10 dias após a dessecação, com doses de 1,29, 1,66 e 1,94 kg e.a. ha-1, que representaram as doses de 0,45, 1,43 e $1,40 \mathrm{~kg}$ e.a. ha $\mathrm{h}^{-1}$ aos 20 dias após a dessecação, respectivamente.

Os resultados deste trabalho estão de acordo com os de Santos et al. (2007), avaliando marandu, Ceccon et al. (2009), avaliando ruziziensis, Silva et al. (2006) e Nunes et al. (2009), avaliando decumbens, pois identificaram a viabilidade do plantio da soja em sucessão entre 7 e 14 dias após a dessecação das forrageiras. Contudo, Constantin et al. (2009) constataram estiloamento de milho semeado após decumbens e redução no crescimento das plantas quando semeado após a aplicação de altas doses de glyphosate. Esse fato restringe a dessecação antecipada de algumas espécies, necessitando-se de maior intervalo entre dessecação da forrageira e plantio da cultura de verão, devido à maior liberação de ácidos orgânicos ao solo durante a 
decomposição da palha, quando esta é excessiva (Damin et al., 2008).

A quantidade de massa deixada pela forrageira (Machado \& Assis, 2010) é importante na implantação da cultura em sucessão, tornando preponderante o pastejo por animais; isso permite, por um lado, a retirada das folhas velhas e a retomada do crescimento vegetal por ocasião do rebrote, o que facilita o controle químico, e, por outro, reduz a quantidade de palha que poderia ocasionar problemas no plantio, como o embuchamento da plantadeira, tanto pela quantidade absoluta de palha quanto por esta não estar aderida ao solo (Aratani et al., 2006). Além disso, a dessecação muito antecipada pode permitir a emergência de novas plantas daninhas, fazendo com que haja necessidade de várias intervenções de controle até o fechamento da cultura (Raimondi et al., 2013).

De maneira geral, os dados deste estudo estão de acordo com Machado \& Assis (2010), que também dessecaram a rebrota das espécies e verificaram que ruziziensis apresentou melhor controle; piatã e tanzânia foram de difícil controle; e decumbens, marandu e mombaça mostraram controle intermediário. No entanto, divergem de Ferreira et al. (2010), que identificaram piatã, MG4, marandu e mombaça como de melhor controle, e tanzânia, decumbens, xaraés e massai, como de mais dificil controle. Salienta-se que ambos os autores realizaram aplicação sequencial com 0,96 e 1,68 kg e.a. ha-1 de glyphosate, respectivamente, após a avaliação, para o plantio em sucessão. Além disso, Machado \& Assis (2010) realizaram a dessecação em outubro, quando as plantas ainda poderiam estar com baixa atividade fisiológica devido ao periodo do ano ainda seco, e Ferreira et al. (2010) realizaram o trabalho em região distinta, dessecando plantas em crescimento livre, o que demanda maiores doses de herbicida, e isso dificulta avaliar efetivamente as doses do produto sobre as espécies.

Entre as forrageiras avaliadas, existem cultivares de uma mesma espécie, como aruana e tanzânia ( $M$. maximum), em diferentes grupos de controle, divergindo de Velini et al. (2000), que estipularam regra geral em que espécies de Megatyrsus requerem maiores doses de herbicidas, comparativamente a espécies de Urochloa, o que leva a supor que esses autores tenham realizado seus trabalhos com mombaça ou tanzânia.

Alguns cultivares de dificil controle, como xaraés e mombaça, apresentaram maior rendimento de massa seca tanto durante o cultivo com milho safrinha quanto com mombaça também na massa da rebrota (Tabela 1), embora sem correlação direta entre massa produzida e dose de herbicida para dessecação. Isso indica o potencial diferenciado de cada cultivar, e sua escolha depende do objetivo para o qual será utilizado. Quando o objetivo é palha para imediata semeadura de uma cultura em sucessão, destacam-se ruziziensis e aruana, pela produção de massa e facilidade de dessecação, porém, quando o objetivo é formação de pastagem, outras espécies podem ser utilizadas.

De acordo com os resultados deste trabalho, as forrageiras podem ser separadas em três grupos por facilidade de controle com o herbicida glyphosate: ruziziensis, massai e aruana, com excelente controle, no primeiro grupo; xaraés, decumbens e marandu, com controle moderado, no segundo; e tanzânia, mombaça e piatã, de dificil controle, no terceiro grupo. Considerando a produtividade de massa durante o cultivo com milho safrinha, o menor período entre a dessecação e avaliação e a menor dose de herbicida, destacam-se ruziziensis e aruana para cultivo da soja em sucessão, aos 10 dias após a dessecação.

\section{LITERATURA CITADA}

ARATANI, R. G. et al. Desempenho de semeadorasadubadoras de soja em Latossolo Vermelho muito argiloso com palha intacta de milho. R. Bras. Eng. Agríc. Amb., v. 10, n. 2, p. 517-522, 2006.

CECCON, G.; STAUT, L. A.; KURIHARA, C. H. Manejo de Brachiaria ruziziensis em consórcio com milho safrinha e rendimento de soja em sucessão. R. Plantio Direto, v. 19, n. 113, p. 4-8, 2009.

CECCON, G. et al. Legumes and forage species sole or intercropped with corn in soybean-corn succession in Midwestern Brazil. R. Bras. Ci. Solo, v. 37, n. 1, p. 204-212, 2013.

CONSTANTIN, J. et al. Sistemas de manejo de plantas daninhas no desenvolvimento e na produtividade da soja. Bragantia, v. 68, n. 1, p. 125-135, 2009. 
DAMIN, V. et al. Nitrogen loss in Brachiaria decumbens after application of glyphosate or glufosinate-ammonium. Sci. Agric., v. 65, n. 4, p. 402-407, 2008.

\section{EMPRESA BRASILEIRA DE PESQUISA AGROPECUÁRIA}

- EMBRAPA. Agropecuária Oeste. Clima MS: banco de dados. Dourados, [2012]. Disponível em: $<$ http:// www.cpao.embrapa.br/clima/>. Acesso em: 14 fev. 2012.

JAKELAITIS, A.; SILVA, A. C.; SILVA, A. A. Eficácia de formulações de herbicidas na dessecação de plantas daninhas. R. Ceres., v. 52, n. 301, p. 421-428, 2005.

FERREIRA, A. C. B. et al. Produção de biomassa por cultivos de cobertura do solo e produtividade do algodoeiro em plantio direto. Pesq. Agropec. Bras., v. 45, n. 6, p. 546-553, 2010.

KOZLOWSKI, L. A. Aplicação sequencial de herbicidas de manejo na implantação da culturado feijoeiro comum em sistema de plantio direto. R. Bras. Herb., v. 2, n. 1, p. 49-56, 2001.

MACHADO, L. A. Z.; ASSIS, P. G. G. Produção de palha e forragem por espécies anuais e perenes em sucessão à soja. Pesq. Agropec. Bras., v. 45, n. 4, p. 415-422, 2010 .

RAIMONDI, M. et al. Controle e reinfestação de plantas daninhas com associação de amonio-glufosinate e pyrithiobacsodium em algodão Liberty Link ${ }^{\circledR}$. R. Bras. Herb., v. 11, n. 2, p. 159-173. Disponível em: $<$ http:// www.rbherbicidas.com.br/index.php/rbh/article/view/178>. Acesso em: 22 jul. 2013.
NUNES, A. S. et al. Épocas de manejo químico de Brachiaria decumbens antecedendo o plantio direto de soja. Planta Daninha, v. 27, n. 2, p. 297-302, 2009.

RIEFFEL FILHO, J. A. et al. Conteúdo de água como indicador da fitotoxicidade de herbicidas inibidores da ALS às plantas de arroz irrigado In: CONGRESSO DE INICIAÇÃO CIENTÍfICA, 14., 2006, Pelotas. Anais... Pelotas: UFPel, 2006. CD ROM.

SANTOS, J. B. et al. Época de dessecação anterior à semeadura sobre o desenvolvimento da soja resistente ao glyphosate. Planta Daninha, v. 25, n. 4, p. 869-875, 2007.

SOUZA FILHO, A. P. S. et al. Inibição da germinação e alongamento da radícula de invasoras de pastagens pelos extratos aquosos de gramíneas forrageiras tropicais. Pasturas Tropicales, v. 19, n. 1, p. 45-50, 1997.

SILVA, A. C. et al. Micorrização e épocas de dessecação de Brachiaria brizantha no desenvolvimento da soja.

Planta Daninha, v. 24, n. 2, p. 271-277, 2006.

SOCIEDADE BRASILEIRA DA CIÊNCIA DAS PLANTAS DANINHAS - SBCPD. Procedimentos para instalação avaliação e análise de experimentos com herbicidas. Londrina: $1995.42 \mathrm{p}$.

VELINI, E. D.; MARTINS, D.; SILVA, M. A. S. Efeito de concentrações de espalhante adesionante e doses de glyphosate no controle de Brachiaria decumbens e Panicum maximum. Planta Daninha, v. 18, n. 2, p. 349-366, 2000.

VOLL, E. et al. Alelopatia do ácido aconítico em soja. Pesq. Agropec. Bras., v. 44, n. 6, p. 645-648, 2009. 